\title{
Prevalence And Determinants of Unintended Pregnancy Among Female High School Students in Arsi Zone, Oromia Regional State, Ethiopia: Cross- Sectional Study
}

\author{
Amana Erreso \\ Adama General medical college \\ Aliye Adem \\ Arsi university \\ Abenet Gurara \\ Arsi university \\ Yirga Amare ( $\nabla$ wonyir@gmail.com ) \\ Arsi university
}

\section{Research Article}

Keywords: Prevalence, Untended pregnancy, Arsi Zone

Posted Date: December 2nd, 2020

DOI: https://doi.org/10.21203/rs.3.rs-109263/v1

License: (c) (1) This work is licensed under a Creative Commons Attribution 4.0 International License.

Read Full License 


\section{ORIGINAL RESEARCH}

2Manuscript title: Prevalence And Determinants of Unintended Pregnancy among Female High 3School Students in Arsi Zone, Oromia Regional State, Ethiopia: Cross-sectional study

\section{Authors:}

5 Amana Aman Erreso, master of maternal and reproductive health ${ }^{1}$

6 Aliye Kediro Adem, master of adult health nursing ${ }^{2}$

7 Abenet Menene Gurara, master of adult health nursing ${ }^{3}$

8Yirga Wondu Amare, masters of maternal and reproductive health ${ }^{4 *}$

$9^{1}$ Lecturer in the department of nursing, Adama general hospital, and medical college, Adama, 10Oromia regional state, Ethiopia

11 E-mail:-amaanaman@yahoo.com

12 Phone: 0910396687

$13^{2}$ Lecturer in the department of nursing, Arsi University, Asella, Oromia regional state, Ethiopia 14 E-mail: aliyekediro@yahoo.com

15 Phone: 0911991305

$16^{3}$ Lecturer in the department of nursing, Arsi University, Asella, Oromia regional state, Ethiopia 17Email: abenetmen@gmail.com

18Phone: 0912820585

$19^{4}$ Lecturer in the department of midwifery, Arsi University, Asella, Oromia regional state, 20Ethiopia

21 E-mail:-wonyir@gmail.com

22 Phone: 0911922520

23*Correspondence: Yirga Wondu Amare

24 Po. box: 04

25 Tel : +251911922520

26 Email: wonyir@gmail.com 


\section{Abstract}

28BACKGROUND: Unintended pregnancy which ends up majorly with induced abortion is the 29leading cause of maternal mortality and morbidity around the globe. Youths are more prone to 30unintended pregnancy because of the rising level of premarital sexual practice across all parts of 31the world. This raising level of premarital sex can be partly explained by the fact that youths face 32various problems in regulating fertility through the use of modern contraceptives. Lack of 33information, socio-cultural, economic barriers in accessing contraceptives, violence as well as 34socio-cultural beliefs impede major role in preventing unintended pregnancy.

350BJECTIVE: To assess the prevalence and determinants of unintended pregnancy among 36 female high school students in Arsi Zone.

37METHODOLOGY: Institutional-based cross-sectional study was conducted between February 38and August 2018 G.C to collect data using a self-administered questionnaire. A multi-stage 39sampling procedure was employed to reach 830 respondents. A bivariate analysis was carried out 40to examine the relationship between unintended pregnancy and explanatory variables. Variables 41that were statistically significant (with $p$-value $<0.05$ ) at the bivariate level were included in the 42multivariate logistic regression to control confounding factors and determine the independent 43determinants of unintended pregnancy among high school students.

44RESULT: Forthy five (30\%) of the respondents reported that they were pregnant at the time of 45the study period. Of the study participants who had been pregnant, 28(62.22\%) students got their 46pregnancy at the age of 16 and 17; and 6(13.33\%) got pregnant at the age of 18 and 19. Age at 47first sexual intercourse, using contraceptive methods, drinking alcohol, chewing kchat, lack of 48knowledge, and failure to discuss reproductive health information with families were significant 49predictors of unintended pregnancy.

50CONCLUSION: The prevalence of unintended pregnancy among the study participants is high 51(29.3\%), and almost all were ended up with abortion. Most reasons reported for having unwanted 52pregnancy were that they were still in school and they don't have money to take care of their 53baby.

54Keywords: Prevalence, Untended pregnancy, Arsi Zone 55 Introduction 
56Unintended pregnancy is a pregnancy that is neither planned nor wanted at the time of 57conception. In most cases, it is a cause for maternal morbidity and adverse feto-maternal 58outcome. Women of all ages may encounter unintended pregnancies but some groups of the 59society such as teenagers are at higher risk. Unintended pregnancies are affected by a number of 60factors including personal beliefs, socio-cultural values, religion, and existing laws in society (1). 61 Now a day, the incidence of unintended pregnancy and abortion particularly in developed 62countries has greatly reduced by using modern contraceptives. Modern contraceptives to those 63who do not have access to them would prevent a large proportion of unintended pregnancies and 64abortions, as well as many maternal and infant deaths $(2,3)$.

65Annually, about 80 million unintended pregnancies are estimated to occur worldwide. In 66developing countries alone more than one-third of all pregnancies are considered unwanted and 67about 19\% will end up in abortion (4). Among the direct cause of maternal death in the world, 68unsafe abortion accounts for $13 \%$ of overall maternal mortality (5). Africa shares more than 40 $69 \%$ of the total global death due to unsafe abortion which puts Africa as a leading region. The 70prevalence of abortion is higher where the unmet need for family planning is high, the 71 contraceptive acceptance rate is low, and less effective contraceptives have been used $(4,6)$. 72Even if contraceptive methods have been used correctly and consistently as recommended, still 73there will be nearly 6 million accidental pregnancies annually which may end up with unwanted 74pregnancy and subsequent abortion(7). Unmarried adolescent girls across all parts of the world 75are more likely prone to rising levels of premarital sexual activities and thus unintended 76pregnancies and unsafe abortion(8). Among women who were admitted to hospitals for 77 management of unsafe abortion complications, 38 to $68 \%$ were under the age of 20 years (9). 78The world health report noted that unwanted, mistimed, and unintended pregnancy is the most 79common cause of maternal mortality in developing countries. According to this report, 80unintended pregnancy was identified much higher in Eastern Africa(118 per 1000 women of 81childbearing age) and middle Africa(94 per 1000) than in the other three sub-regions: Northern, 82Southern, and West Africa where the rate ranges between 56 and 83 per 1000(10). For this 83reason, unintended pregnancy is an important public health issue especially, in developing 84countries because of its negative association with social and health outcomes for both the mother 85and child (11). Unintended pregnancy among adolescents is a global health problem that affects 86not only girls but also their families and society at large. Even though there are disparities in 87magnitude and consequence between countries, unintended pregnancy is a challenge for every 
88society (12). In sub-Saharan Africa, it is estimated that 14 million unwanted pregnancies occur 89every year with almost half occurring in women age 15-24 years (13). Despite several 90international declarations and abortion laws, many women in developing countries are still 91victims of unwanted pregnancies and complications of unsafe abortion (14). Even though the $5^{\text {th }}$ 92MDG is targeted to reduce maternal mortality by three-fourth by 2015 , Ethiopia had the $5^{\text {th }}$ 93largest number of maternal deaths in the world which was estimated to be 676 deaths per 94100,000 live births in the yea 2011(15).

95The EDHS report showed that $16.2 \%$ and $18.7 \%$ of women reported that their last pregnancy 96was unwanted and mistimed respectively (14). Another study in Ethiopia also pointed out that 97 more than $40 \%$ of pregnancies are unintended and only $14 \%$ of the reproductive age women use 98birth control methods (16). Peer influence, poor school-based sexual education, and poor 99parental involvement in preparing young people for safe sexual life are factors that lead an 100adolescent to unintended pregnancy (13). Substance use, living arrangement, age of students, 101school performance, having pocket money, watching pornographic video, place of the family 102residence, and parental education status are also factors of unintended pregnancy $(13,17)$. 103Similarly, unintended pregnancy is higher among women who are unmarried, lower economic 104status, at an early or late age of reproductive life, and among those who attend formal education 105(15). Even though continued attention has been given to reproductive health issues, maternal and 106reproductive status in most of the world remains dismal. Still, the problem of unwanted 107pregnancy and induced abortion at the community and school is believed to be very high but 108underreport, limited data sources and inaccurate information on the event are the major obstacles 109to obtain the actual figure.

110Moreover, there are limited numbers of literature dealing with unintended pregnancy among high 111school students. Having this information in mind, the aim of this study will be to address the 112clear knowledge gap on the prevalence and determinants of unintended pregnancy among female 113high school students.

\section{Material and methods}

115An Institutional based cross-sectional survey was conducted to assess the prevalence and 116determinants of unintended pregnancy among female high school. 
118The sample size was calculated using the formula for a single population proportion by 119taking the proportion for unintended pregnancy among female adolescents $37.8 \%$ (14), 120 with a confidence interval of $95 \%$ and a degree of precision of $5 \%$. Finally, the design 121 effect of 2 was taken and $10 \%$ was added to the sample size for non-response rate and 122possible absenteeism compensation to yield the final sample size of 830. A multistage 123sampling procedure was employed to select a representative sample of female adolescent 124students (stratification into grades and simple random sampling to select sections and 125respondents were selected systematically from their sections). Five districts/towns were 126selected out of 26 woredas in Arsi Zone using simple random sampling, identified by 127name i.e. (Lode Hetosa, Bekoji, Arsi Robe, Hetosa, and Asella). Then from each five 128selected districts, one secondary and preparatory schools were selected using a simple 129random sampling technique. The calculated sample size was distributed proportionally to 130each selected schools based on the number of students they had. Each school was 131 stratified by grade i.e. grades $9,10,11$, and 12 . The proportional allocation of the sample 132was assigned to the respective grade. Two sections were randomly selected from each 133grade and all-female students were included in the study. Using students list respondents 134 were selected by a systematic random sampling method. Data was collected using a self135administered questionnaire that had both close and open-ended questions. Data collectors 136and supervisors were trained on the objective of the study and maintaining 137confidentiality. Students who gave their verbal informed consent were provided with 138written, self-administered questionnaires. Research instruments and research procedures 139were pretested with the whole research team, including research assistants. The 140 completeness of the data was analyzed and sorted properly. Data was entered into the 141computer twice before processing and analysis to avoid mistakes. The collected data was 142entered into the computer using EPI Info version 7.0 in order to ensure its accuracy then 143transported to the Statistical package for social science(SPSS version 21.0) software for 144analysis. Descriptive statistics were computed to determine frequencies, percentages, and 145mean of the variables. A Bi-variate analysis was carried out to examine the relationship 146between unintended pregnancy and explanatory variables. Variables that were 147statistically significant (with p-value $<0.05$ ) at the bivariate level were included in the 
148multivariate logistic regression to control confounding factors and determine the 149independent determinants of unwanted pregnancy among students.

150Ethical approval involving human study and protocol was obtained from Adama general 151hospital and medical college research and ethical review committee in accordance to the 152national protocol.

\section{Results}

\section{Socio-demographic information on female high school students}

155A total of 830 female adolescents aged from15-24 years participated a response rate of $156100 \%$., and the respondents' mean age was 17.29 years, of all respondents $686(82.65 \%)$ 157were between 15 and 24 years old; and 144(17.35\%) were between 19 and 24years old. 1580f all 250(30.1\%) were grade 9th students; 240(28.9\%) were grade 10th students, $159171(20.6)$, and $169(20.4)$ were grade $11^{\text {th }}$ and $12^{\text {th }}$ students respectively.

1600 f 830 respondents, $770(92.8)$ of respondents' fathers were alive during the survey. 161When we see fathers' educational status, there were about 217(28.2\%) students' fathers 162had college and above educational levels; 159(20.65\%) were attended high school; 163245(31.82\%) were attended elementary school while 147(19.2\%) of respondents' father

164 were illiterate. With regards to students' father's job, the majority of students' fathers were 165farmers, 362(47.01\%); 211(27.4\%) were governmental employees; 95(12.34\%) were 166merchants; $80(10.39 \%)$ and 22(2.86\%) were a private employee and others respectively. 167The majority of students' fathers earned more than three thousand birrs, 146(18.96\%).

1680f the total participants' mothers, 798(96.1\%) were alive. Of these mothers, 199(24.96\%) 169were illiterate; and 295(36.97\%), 205(25.69\%), and 99(12.41\%) had elementary, high 170school, and college and more educational levels respectively. Unlike students' father, the 171majority of students' mother 334(41.85\%) were housewife, $147(18.42 \%$ were farmers; 172114(14.29) and 112(14.04\%) mothers were merchants and governmental employee 173respectively; $89(11.15 \%)$ of respondent' mother were a private employee and $2(0.25 \%)$ 174were others [Table-1]

175

176Reproductive Health History and Contraceptive use among Study 177Participants 
1780f the total study participants, 150(18.1\%) of them reported having had sexual 179experience at the time of the survey. The mean age of first pregnancy among study 180participants was 16.76 . Of total students who had been pregnant, $28(63.64 \%)$ pointed out 181that never think of pregnancy was their major reasons for not to control the unintended 182pregnancy, 9(20.45\%) of them had reported that their incidental practice of sexual 183intercourse was their reasons for the occurrence of unintended pregnancy. Of all students 184who had been pregnant, almost all were unwanted 44(97.78\%) while only $1(2.22 \%)$ of 185them were wanted. It was reported that a big number of abortions were taking place at 186private clinic 20(44.44\%); $9(20 \%)$ of the respondents aborted at a private home; $1872(4.44 \%), 7(15.55 \%)$, and $6(13.64 \%)$ abortion were taken place at the health center, 188hospital, and others (Marie stops) respectively.

189The mean age of menarche among study participants was age14.1. Among the study 190participants, only $279(33.6 \%)$ of them knew when pregnancy occurs in relation to the 191menstruation cycle. 392(47.2\%) of study participants had discussed reproductive health. 192The majority of participants discuss reproductive health issues with their friends, 193138(35.2\%); 77 (19.64\%) of them discussed with their mothers, and 27(6.89\%), and 19419(4.85\%) talked with their sisters and fathers, respectively.

195More than two-thirds of the study participants did not drink alcohol, 789(95.1\%). Of the 196total study participants only 41(4.9\%) female students drink alcohol, 39(4.7\%) of them 197chewed kchat; 96(11.6\%) of them watched pornographic movies, and 2(0.2\%) uses others 198(hashish, etc). 96(11.57\%) of sexually active students used contraceptives during they 199had sexual intercourse.

200Of the total respondents, only 55(6.6\%) had used emergency contraceptive. [Table -2]

\section{Prevalence of unwanted pregnancy among respondents}

202Of the total respondents, $45(5.42 \%)$ of them became pregnant at some point in their lives. 203Among women who had been pregnant almost all were unwanted 44(97.8\%), and among 204women who had ever had unwanted pregnancy 44(97.8\%) of them were reported that the 205pregnancy was terminated. Of these, all of them were induced abortion. [Figure-1 and 2] 206Factors related to unwanted pregnancies among respondents

207The majority of the respondents who did not want pregnancies were still in school $20829(65.9 \%)$ followed by $4(9.1 \%)$ fear of social isolation; $3(6.82 \%)$ who did not have 
209money to take care of their baby; $3(6.82 \%)$ were due to rape; $1(2.27 \%)$ were not wanted 210their pregnancy to have a gap between births and others $4(9.1 \%)$ of them were due to 211divorce, being single, etc.

\section{Relationship between socio-demographic factors and unintended 213pregnancy}

214In the bivariate logistic regression, students' age and parents' demographic characteristics, 215mother's (educational level and salary) had a significant association with unintended 216pregnancy at 95\% CI COR. However, in multivariate logistic regression students' grades, 217students' mothers' educational level had only a significant association with students' 218unintended pregnancy.

219Regarding the level of students' mothers' education, students whose mothers were 220illiterate were more likely to get unwanted pregnancy [AOR $=0.16$; 95\% $\mathrm{CI}=0.04,0.66$ ]; 221and students whose mother were elementary schools in education were also more likely 222to experience unwanted pregnancy as compared with students whose mothers were 223secondary school and came from college and more $[\mathrm{AOR}=0.07 ; 95 \% \mathrm{CI}=0.01,0.56]$ 224[Table-3].

\section{Relationship between Reproductive health issues and Contraceptive use 226with unwanted pregnancy among respondents}

227There was a positive association between alcohol drinking, kchat chewing, and watching 228pornographic movies with ever having an unintended pregnancy. Students who 229mentioned fell in love as their main reason for sexual intercourse activity were more 230likely to experience unintended pregnancy than students who reported peer pressure, 231marriage, and benefits as their major sexual reasons $[\mathrm{AOR}=0.05 ; 95 \% \mathrm{CI}=0.01,0.6]$.

232Study participants who drank alcohol were three times more likely to experience 233unintended pregnancy as compared to those who did not drink alcohol $[\mathrm{AOR}=3 ; 95 \% \mathrm{CI}$ : $2341.86,13.0]$. Students who chew kchat were 2.5 times more likely to experience 235unintended pregnancy as compared to those who did not chew kchat $[\mathrm{AOR}=2.5 ; 95 \%$ $236 \mathrm{CI}=1.4,3.0]$.

237Knowledge of pregnancy occurrences in relation to the menstruation cycle was an 238independent determinant of unintended pregnancy among students. Students who were 
239not knowledgeable were nearly two times more likely to get unintended pregnancy than 240those who did know [AOR=1.6; 95\% CI: 1.02, 2.3]. Students who did not discuss 241reproductive health information were almost two times more likely to get unintended 242pregnancy [AOR=2.38; 95\%:1.38, 4.13].

243Students who had ever used a contraceptive method were less likely to have experienced 244unintended pregnancy than those who had never used contraceptive methods 245[AOR $=0.065 ; 95 \%$ CI: 0.034, 0.121]. [Table-4]

\section{Discussion}

\section{Prevalence of unintended pregnancy and induced abortion among 248female high school students in Arsi Zone}

249 This study was conducted to determine the prevalence and associated factors with 250 unintended pregnancy among female high school students in Arsi Zone. Eight hundred

251 thirty representative samples were selected from five districts in Arsi zone (five 252 secondary and preparatory schools) using multistage probability sampling techniques 253 (stratification alongside simple random sampling techniques).

254 In this study, 44(29.3\% ( \pm 3.3 ; at $\alpha 95 \% \mathrm{CI})$ of the study participants reported that they 255 had ever experienced unintended pregnancy at the time of the study. Of all unintended 256 pregnancies, almost all were ended up with induced abortion with a proportion of 257 44(97.8\%). This meant only one study participant with unintended pregnancy gave 258 birth.

259 This finding is comparable to a study conducted in Tanzania states $27.1 \%$ of 260 pregnancies were unintended (18) but it is less magnitude than a study conducted in

261 shire town as $33 \%$ of pregnancies were unintended and $87 \%$ of them ended up with 262 induced abortion (3).

263 Another study conducted in Soweto, South Africa revealed 23\% of pregnancies occur at 264 age $13-16$ and $14.9 \%$ occur at age 17-19 (3). This finding is not coinciding with the 265 current study result in which $62.22 \%$ of pregnancy occurs at age of $16-17$ and $22.22 \%$ 266 at age of 18-19. 
267 In this study, a total of $18.1 \%$ of female students had engaged in sexual intercourse and $26830 \%$ of them get pregnant. Of all pregnancies, 98.8\% were unintended, which has

269 greater magnitude as compared with a cross-sectional study conducted in Wachamo 270 University, showed that $39 \%$ of female students had sexual intercourse and $12.58 \%$ of 271 them got pregnant, and 91.4\% were unintended (4). And also the magnitude of 272 unintended pregnancy among adolescent high school students is greater than a study 273 result done in the Ethiopian hospitals showed that there were $37.8 \%$ unwanted 274 pregnancies among female youths and from which 50\% were induced abortions (14).

275 And it has also a smaller magnitude as compared with a cross-sectional study 276 conducted in Harar, Eastern Ethiopia which showed 33.3\% unintended pregnancies and $27750 \%$ induced abortion(18). However, it is inconsistent with a study conducted on 278 adolescents in Addis Ababa which indicated that $50 \%$ of unintended pregnancy and $27974 \%$ of these pregnancies ended up with abortion (2).

280 In the current study, the magnitude of adolescents' unintended pregnancy is less. As 281 compared to previous studies; it is likely that the levels observed here in this study 282 might be underestimated the magnitude of unintended pregnancy among high school 283 students, this might be due to the unwillingness of adolescent female students to report 284 having had an unintended pregnancy or an abortion since it is sensitive and personal 285 issues. The mean age of the first unintended pregnancy among study participants was $28616.75( \pm 0.22,95 \% \mathrm{CI})$. Of the pregnant study participants, $28(62.22 \%)$ students got 287 unintended pregnancy at the age of 16 and 17 . Whereas another cross-sectional study 288 conducted among preparatory school in Addis Ababa showed that the mean age of the 289 first pregnancy among study participants was 17 which are 59\% (14). In this study, of 290 all pregnant adolescent students, 28(63.64\%) pointed out that never think of pregnancy

291 was their major reasons for not to control unintended pregnancy and having 292 irregular/incidental sexual intercourse as their major reasons for unintended pregnancy 293 was $9(20.45 \%)$.

\section{Determinants of unintended pregnancy among female high school 295students in Arsi Zone}

296 In the multivariate logistic regression students' age, grade, and parents' demographic 297 characteristics (mother's educational level and salary), drinking alcohols, smoking 
298 cigarette, chewing kchat, watching pornographic movies, age at first sexual intercourse,

299 knowledge of pregnancy in relation to the menstrual cycle, discussion on reproductive 300 health, and practice of contraceptive were significantly associated with students' 301 unintended pregnancy.

302 Related to students' family demographic characteristics, the father's, and mother's 303 educational status had a statistically significant association with students' unintended 304 pregnancy. Regarding the level of students' mothers' education, students whose 305 mothers were illiterate were more likely to get unwanted pregnancy [AOR $=0.16 ; 95 \%$ $306 \mathrm{CI}=0.04,0.66]$; and students whose mothers were elementary schools in education were 307 also more likely to experience unwanted pregnancy as compared with students whose 308 mothers secondary school and came from college and more $[\mathrm{AOR}=0.07 ; 95 \% \mathrm{CI}=0.01$, 309 0.56]. This means that the relationship between the level of students' mothers' education 310 and students to be unintended pregnant is negative, when mothers' level of education 311 increases, getting unintended pregnancy decreases.

312 In this study, among adolescent female students, $84.4 \%$ of unwanted pregnancy occurs 313 at age of 15-18 years. This is consistent with the study conducted in Tanzania which 314 showed $80 \%$ of female youths (15-18years) exposed to unwanted pregnancy (18). 315 Although in this study students' age at first sexual intercourse was significantly 316 associated with students' unintended pregnancy, students whose age ranged from 16-17

317 at their first sexual intercourse were more likely to be exposed to unintended pregnancy 318 than those whose age ranged from 18-19 years at first sexual intercourse [AOR $=0.32$; $31995 \% \mathrm{CI}=0.10,0.99]$. There was a positive association between alcohol drinking, 320 chewing kchat, and watching pornographic movies with ever having an unintended 321 pregnancy. In the current study, participants who drank alcohol were three times more 322 likely to experience unwanted pregnancy as compared to those who did not [AOR $=3$; $32395 \%$ CI: 1.86, 13]. This might be due to the consumption of alcohol that may distort 324 their decision and lead to unsafe sexual practice. In confirmation with this study, a 325 student-based study conducted among female preparatory students in Addis Ababa 326 revealed that those female students who drink alcohol last week before the study were 327 three times more likely to have had unintended pregnancy than those who never drank 328 alcohol; students who chew kchat and who did not discuss reproductive health were 
329 more likely to experience unwanted pregnancy as compared to those who did not chew

330 and discuss (13). Students who watch pornographic movies were 2.6 times more likely

331 to experience unintended pregnancy than those who were not $[\mathrm{AOR}=2.9 ; 95 \% \mathrm{CI}=1.9$,

332 4.4]. In this study, the contraceptive utilization result is very low. This might be due to

333 less awareness of female high school students about modern contraceptives. The

334 association between contraceptive use and unintended pregnancy was found to be

335 statistically significant. Students who had not used a contraceptive method were more

336 likely to have had unwanted pregnancy [AOR $=0.061 ; 95 \%$ CI: $0.031,0.12]$. This result

337 is consistent with a study conducted among preparatory school in which students who

338 had ever used contraceptive methods were less experienced unwanted pregnancy (13).

\section{Conclusion}

340The prevalence of unintended pregnancy among female high school students is high $34129.3 \%$, and most of the induced abortion was the result of unwanted pregnancy.

342There was low utilization of contraceptives among female students and its association 343with unwanted pregnancy was statistically significant. Students' age, grade, and students' 344mothers' educational level and salary, drinking alcohols, smoking cigarette, chewing 345kchat, watching pornographic movies, age at first sexual intercourse, knowledge of 346pregnancy in relation to menstruation cycle, discussion on reproductive health, and 347practice of contraceptive were significantly associated with students' unintended 348pregnancy.

349Students who were single were more likely to have an unwanted pregnancy and induced 350abortion. Most of the reason given by the respondents for having unintended pregnancy 351and subsequent abortion was that they were still school and they did not have money to 352take care of the baby.

\section{LIST OF ACRONYMS}

354AGHMC.................Adama General Hospital and Medical College

$355 \mathrm{CI}$ .Confidence Interval

356CPR Contraceptive Prevalence rate 
357CSA......................entral Statistics Agency

358DC Data Collector

359EC Emergency contraceptive

360EDHS Ethiopian Demographic Health Survey

361FHI Family Health International

$362 \mathrm{GO}$ Governmental organization

363ICPD International conference on population development

364IPPF International Planned Parenthood Federation

365MDGs Millennium Development Goals

366MMR Maternal Mortality Ratio

$367 \mathrm{MOH}$ Ministry of Health

368NGOs Non-governmental Organization

369OR Odds Ratios

370PI Principal Investigator

371RH Reproductive Health

372SPSS Statistical Package for Social-Science

373SSA Sub-Sahara Africa

374STI Sexually Transmitted Infection

375U.S.A United States of America

376UN United Nation

377UNFPA United Population Fund Agency 
378WHO World Health Organization.

\section{Declarations}

\section{Ethics approval and consent to participate}

381An approval letter was obtained from Adama General Hospital and Medical College 382Ethical and review committee. At all levels, officials were contacted and permission was 383secured. Purpose, objective, and the benefit of the study were explained to the study 384subjects adequately and their both their verbal and written consent was obtained for those 385 students aged $\geq 18$ years. For students age between 15 and 18 years, consent wavier was 386obtained from Adama general hospital and medical college research and ethical review 387committee by considering the data collection procedure does not harm the minors. 388Consent for publication

389 Not applicable

\section{Availability of data and materials}

391 Datasets are available from the corresponding author upon reasonable request

\section{Competing interests}

393All the authors declare that there is no conflict of financial and other interests

\section{Funding}

395 It is a self-funded project

\section{Authors' contributions}

397 Amana Aman took part in conceptualization, proposal writing, searched the database, 398supervised data collectors, analyzed, interpreted results and wrote the first draft of the 399article. Aliyi Kediro was responsible in the proposal writing, supervision during data 400collection, analysis and interpretation of findings, writing and approval of the final 
401version of the article. Abnet Menene participated in supervision, analysis, editing, 402writing, and approved the final version of the article. Yirga wondu was also involved in 403supervision, data entry and cleaning, analysis and interpretation and approval of the final 404version, manuscript preparation and served as a corresponding author.

\section{Acknowledgment}

406We would like to present our deepest appreciation to Arsi Zone administration, Arsi Zone 407education office, and Zonal health bureau for their cooperation. Our thanks also go to 408school directors and students who were volunteer, and cooperative in providing necessary 409data to our studies.

\section{References}

411 1- Baginski LJ. Pregnancy planning, Medicine home>Women health Page. C 1996412 2007. Medicine Net. (2007).

413 2- Allan Guttmacher Policy Review (2007), Volume 10, Number 3.

414 3- Hadgu G, et al. "Determinants of unwanted pregnancy and induced abortion among 415 female youths in Shire town, Tigray, Ethiopia." World journal. of pharm. and med. 416 Research. (2015). Vol. 2(2455-3301).

417 4- Mitiku S, Demissie M, Belayneh F, Meskele M. "Prevalence of Induced Abortion 418 and Associated Factors among Wachamo University Regular Female Students, 419 Southern Ethiopia.” Journ. of Pharm. and Alt. Med. (2015). Vol.7 (2222-5668).

420 5- Eyob Tadesse and S Negussie. "Adolescent pregnancies in Addis Ababa". East 421 African Medical Journal. August (2007). Vol.7 (8):431-34

422 6- Tesfaye G, Hambisa MT, Semahegn A. "Induced Abortion and Associated Factors 423 in Health Facilities of Guraghe Zone, Southern Ethiopia.” Journal of pregnancy. 424 (2014). 
425 7- World Health Organization (WHO). Safe abortion: technical and policy guidance for

426 health systems. Geneva: World Health Organization, 2003.

427 8- Ethiopia Demographic and Health Survey. Addis Ababa, Ethiopia, and Calverton,

428 Maryland, USA: Central Statistical Agency and ICF International. 2011.

429 9- Mustafa Adelaja Lamina. "Prevalence and determinants of unintended pregnancy 430 among women in South-Western Nigeria." Maternal and Fetal Health Unit, 431 Department Of Obstetrics and Gynaecology, Olabisi Onabanjo University Teaching 432 Hospital, Sagamu, Nigeria. Ghana Med. J. 2015 Sept. Vol. 49(3).

433 10-Tebekaw et al.: "Prevalence and determinants of unintended childbirth in Ethiopia." 434 BMC Pregnancy and Childbirth. (2014) 14:326.

435 11-Hamdela B, Tilahun T. "Unwanted pregnancy and associated factors among 436 pregnant married women in Hosanna Town, Southern Ethiopia." PLOS ONE. 2012; 437 7(6):e39074.

438 12-Mary Philip Sebastian, M.E. Khan, and Daliya Sebastian. "Unintended Pregnancy 439 and Abortion in India with Focus on Bihar, Madhya Pradesh, and Odisha." New 440 Delhi, India: Population Council. 2013.

441 13-Sara Kahasay. "Assessment of magnitude and factors associated with unintended 442 pregnancy among preparatory high school students, Addis Ababa, Ethiopia." 443 Dissertation, Department of Nursing and Midwifery, Addis Ababa University. June 4442015.

445 14- Teshale Mulatu. "Prevalence of unwanted pregnancy and associated factors among 446 women in reproductive age groups at selected health facilities in Addis Ababa city, 447 Ethiopia." Dissertation, Department of Nursing and Midwifery, Addis Ababa $448 \quad$ University, June (2014).

449 15-Ethiopia Central Statistical Agency and ICF International. 2012. 2011

450 16-Brown H, Coulson J, Gordon-Maclean C, Nyalali K, Maternowska C, and Testa A. 451 "Unintended pregnancy among teenagers in Arusha and Zanzibar, Tanzania: A 452 situational analysis.” London: Marie Stopes International. 2013.

453 17-Frehiwot B, Yigeremu A, Reta A, Wuleta L, Tamrat A, Tewodros G. "Khat and 454 alcohol use and risky sexual behavior among in-school and out-of-school youth in 455 Ethiopia. BMC Public. 
456 18-Dr. Neema Mamboleo. "Unwanted pregnancy and Induced abortion among female 457 youths: a case study of Temeke District, Dar es Salaam, Tanzania.” Dissertation 458 submitted in fulfillment of the requirements for the degree of Master of Public 459 Health (MPH), Muhimbili University of Health and Allied Sciences, November 4602012.

461 19-Solomon W., Mesganaw F. "Unintended pregnancy and induced abortion in a town

462 with accessible family planning services: The case of Harare town in eastern

463 Ethiopia.” Ethiopia J. Health Dev. 2006; 20(2): 79- 83.

464 


\section{Tables}

467Table1: Socio-demographic characteristics of female students in Arsi Zone High 468Schools

469

470

471

\begin{tabular}{|c|c|c|}
\hline Demographic Characteristics & Freq. & $\%$ \\
\hline Age $15-18$ years & 686 & 82.65 \\
\hline 19-24 years & 144 & 17.35 \\
\hline Total & 830 & 100 \\
\hline \multicolumn{3}{|l|}{ Religion; $\mathbf{N}=830$} \\
\hline Muslim & 201 & 24.2 \\
\hline Orthodox & 536 & 64.6 \\
\hline Protestant & 85 & 10.2 \\
\hline Catholic & 4 & 0.5 \\
\hline Others & 4 & 0.5 \\
\hline Total & 830 & 100 \\
\hline \multicolumn{3}{|l|}{ Level of Education (Grade); $N=830$} \\
\hline Ninth & 250 & 30.1 \\
\hline Tenth & 240 & 28.9 \\
\hline Eleventh & 171 & 20.6 \\
\hline Twelfth & 169 & 20.4 \\
\hline Total & 830 & 100 \\
\hline \multicolumn{3}{|l|}{ Marital status; $\mathbf{N}=\mathbf{8 3 0}$} \\
\hline Married & 41 & 4.9 \\
\hline Single & 701 & 84.5 \\
\hline Cohabitant & 83 & 10 \\
\hline Widowed & 1 & 0.1 \\
\hline Divorced & 4 & 0.5 \\
\hline Total & 830 & 100 \\
\hline \multicolumn{3}{|l|}{ With whom are you living?; $\mathrm{N}=830$} \\
\hline Both parents & 609 & 73.4 \\
\hline Mothers only & 66 & 8 \\
\hline Fathers only & 9 & 1.1 \\
\hline Relative & 52 & 6.3 \\
\hline Husband & 9 & 1.1 \\
\hline Boy friend & 4 & 0.5 \\
\hline Friend & 21 & 2.5 \\
\hline Alone & 38 & 4.6 \\
\hline Other & 22 & 2.7 \\
\hline Total & 830 & 100 \\
\hline
\end{tabular}

472Table 2: Reproductive Health History and Contraceptive use among respondents 


\begin{tabular}{|c|c|c|c|}
\hline \multicolumn{4}{|c|}{ Age of first sexual intercourse; $N=150$} \\
\hline & $<14$ years & 2 & 1.33 \\
\hline & $14-15$ years & 29 & 19.33 \\
\hline & $16-17$ years & 87 & 58 \\
\hline & 18-19 years & 29 & 19.33 \\
\hline & $>19$ years & 3 & 2 \\
\hline \multicolumn{2}{|l|}{ Total } & 150 & 100 \\
\hline \multicolumn{4}{|c|}{ Main reason for sexual intercourse at the first time you } \\
\hline \multirow[t]{6}{*}{ had it; $N=150$} & Marriage & 15 & 10 \\
\hline & Rape & 15 & 10 \\
\hline & Felt in Love & 83 & 55.34 \\
\hline & Peer pressure & 29 & 19.33 \\
\hline & To get Benefit & 6 & 4 \\
\hline & To get grade/mark & 2 & 1.33 \\
\hline \multicolumn{2}{|l|}{ Total } & 150 & 100 \\
\hline \multicolumn{4}{|c|}{ Age of First pregnancy; $N=45$} \\
\hline & 15 years & 7 & 15.56 \\
\hline & 16 years & 14 & 31.11 \\
\hline & 17 years & 14 & 31.11 \\
\hline & 18 years & 4 & 8.89 \\
\hline & $\geq 19$ years & 6 & 13.33 \\
\hline \multicolumn{2}{|c|}{ Total } & 45 & 100 \\
\hline \multicolumn{4}{|c|}{ Why did not control the pregnancy; $N=44$} \\
\hline \multicolumn{2}{|c|}{ Rape } & 2 & 4.55 \\
\hline \multicolumn{2}{|c|}{ Forgetting pills } & 4 & 9.1 \\
\hline \multicolumn{2}{|c|}{ Failed condom } & 1 & 2.27 \\
\hline \multicolumn{2}{|c|}{ It was irregular sex } & 9 & 20.45 \\
\hline \multicolumn{2}{|c|}{ Never think of it } & 28 & 63.64 \\
\hline \multicolumn{2}{|l|}{ Total } & 44 & 100 \\
\hline \multicolumn{4}{|c|}{ Reason for not using contraceptive $\quad \mathrm{N}=734$} \\
\hline Too & young to attend FP clinic & 481 & 65.53 \\
\hline
\end{tabular}




\begin{tabular}{|c|c|c|c|}
\hline & No knowledge about contraceptives & 31 & 4.22 \\
\hline & Contraceptives not available & 16 & 2.18 \\
\hline & Fear of side effects & 17 & 2.32 \\
\hline & Social influences/accused of immoral behavior & 76 & 10.36 \\
\hline & Others & 113 & 15.4 \\
\hline Total & & 734 & 100 \\
\hline
\end{tabular}

473

474Table-3: Association between demographic factors and unwanted pregnancy among 475study participants.

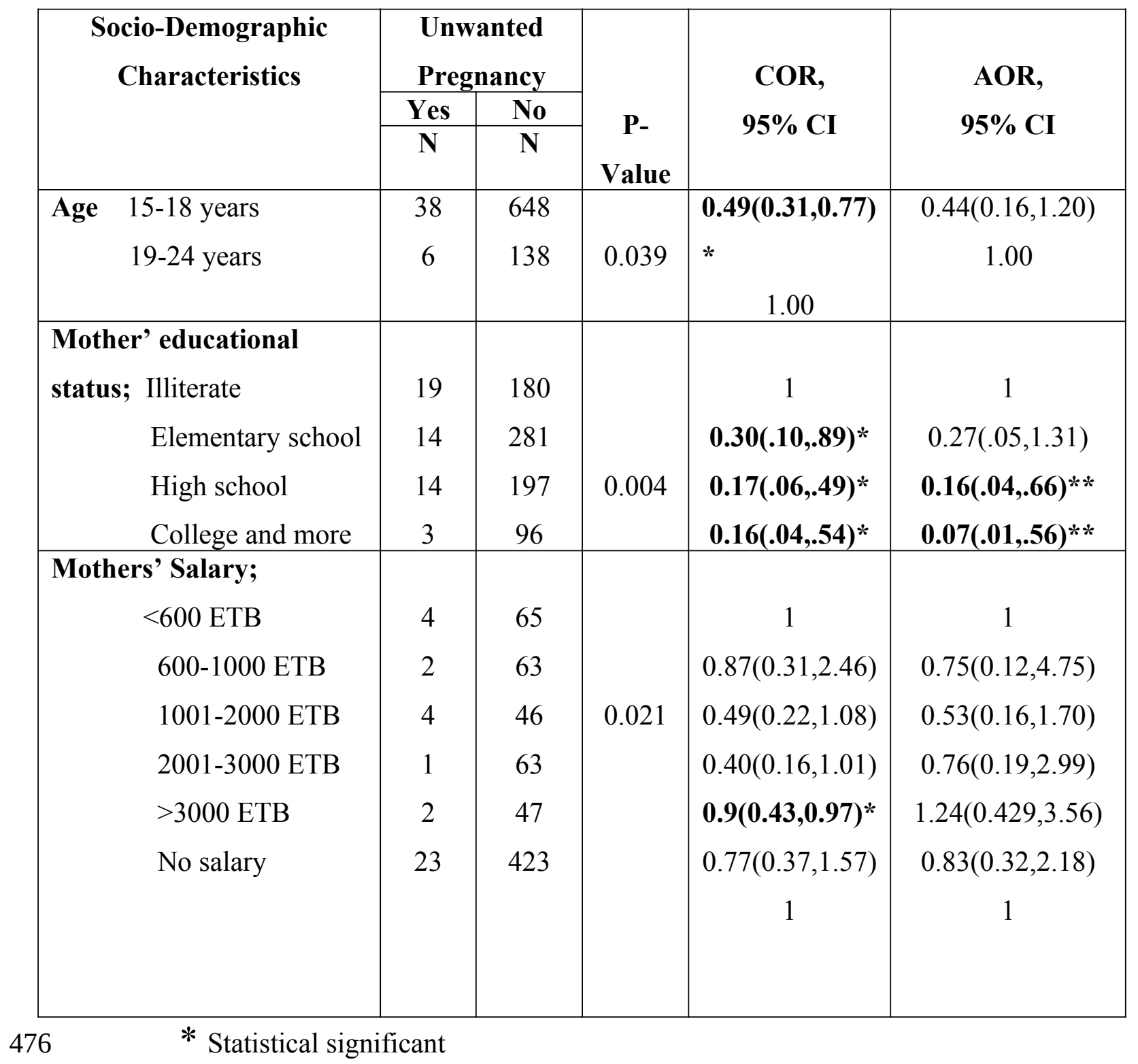


477Table-4: Association between reproductive health history and contraceptive use factors

478with unwanted pregnancy

\begin{tabular}{|c|c|c|c|c|c|c|}
\hline \multirow{3}{*}{\multicolumn{2}{|c|}{ Sexual Behavior and Substance }} & \multicolumn{2}{|c|}{$\begin{array}{l}\text { Unintended } \\
\text { Pregnancy }\end{array}$} & \multirow{3}{*}{$\begin{array}{c}P- \\
\text { value }\end{array}$} & \multirow{3}{*}{ COR 95\% CI } & \multirow{3}{*}{ AOR, 95\% CI } \\
\hline & & Yes & No & & & \\
\hline & & $\mathbf{N}$ & $\mathbf{N}$ & & & \\
\hline \multicolumn{7}{|c|}{ Age of first sexual intercourse; } \\
\hline & $<14$ years & --- & 2 & & 1 & 1 \\
\hline & $14-15$ years & 9 & 20 & & $0.20(.04,1.12)$ & $0.79(.06,9.14)$ \\
\hline & $16-17$ years & 27 & 60 & & $0.22(.11, .44) *$ & $0.32(.10, .99) * *$ \\
\hline & 18-19 years & 7 & 22 & 0.012 & 1 & 1 \\
\hline & $>19$ years & 1 & 2 & & 1 & 1 \\
\hline \multicolumn{7}{|c|}{$\begin{array}{l}\text { During regular menstruation } \\
\text { when pregnancy occurs? }\end{array}$} \\
\hline Knov & vledgable & 18 & 261 & & 1 & 1 \\
\hline Not $\mathrm{k}$ & knowledgable & 26 & 525 & 0.001 & $1.6(1.02,2.46)$ & $1.6(1.02,2.3)$ \\
\hline \multicolumn{7}{|c|}{ Had RH discussion; } \\
\hline & Yes & 12 & 380 & & 1 & 1 \\
\hline & No & 32 & 406 & 0.000 & $2.37(1.37,4.09)$ & $2.38(1.38,4.13)$ \\
\hline \multicolumn{7}{|c|}{ Family planning use } \\
\hline & Yes & 15 & 81 & & 1 & 1 \\
\hline & No & 29 & 705 & 0.002 & $0.06(.03, .12)^{*}$ & $0.061(.031, .12) * *$ \\
\hline \multirow{4}{*}{$\begin{array}{l}\text { Types of } \\
\text { Substance } \\
\text { used }\end{array}$} & $\begin{array}{r}\text { Alcohol; } \\
\text { Yes }\end{array}$ & 33 & 8 & 0.000 & $7(3,13)$ & $3(1.86,13)$ \\
\hline & No & 11 & 767 & & 1 & 1 \\
\hline & $\begin{array}{l}\text { Pornographic } \\
\text { Movies; Yes }\end{array}$ & 31 & 65 & 0.000 & $3.8(2.6,5.6)$ & $2.9(1.9,4.4)$ \\
\hline & No & 13 & 721 & & 1 & 1 \\
\hline
\end{tabular}

480 


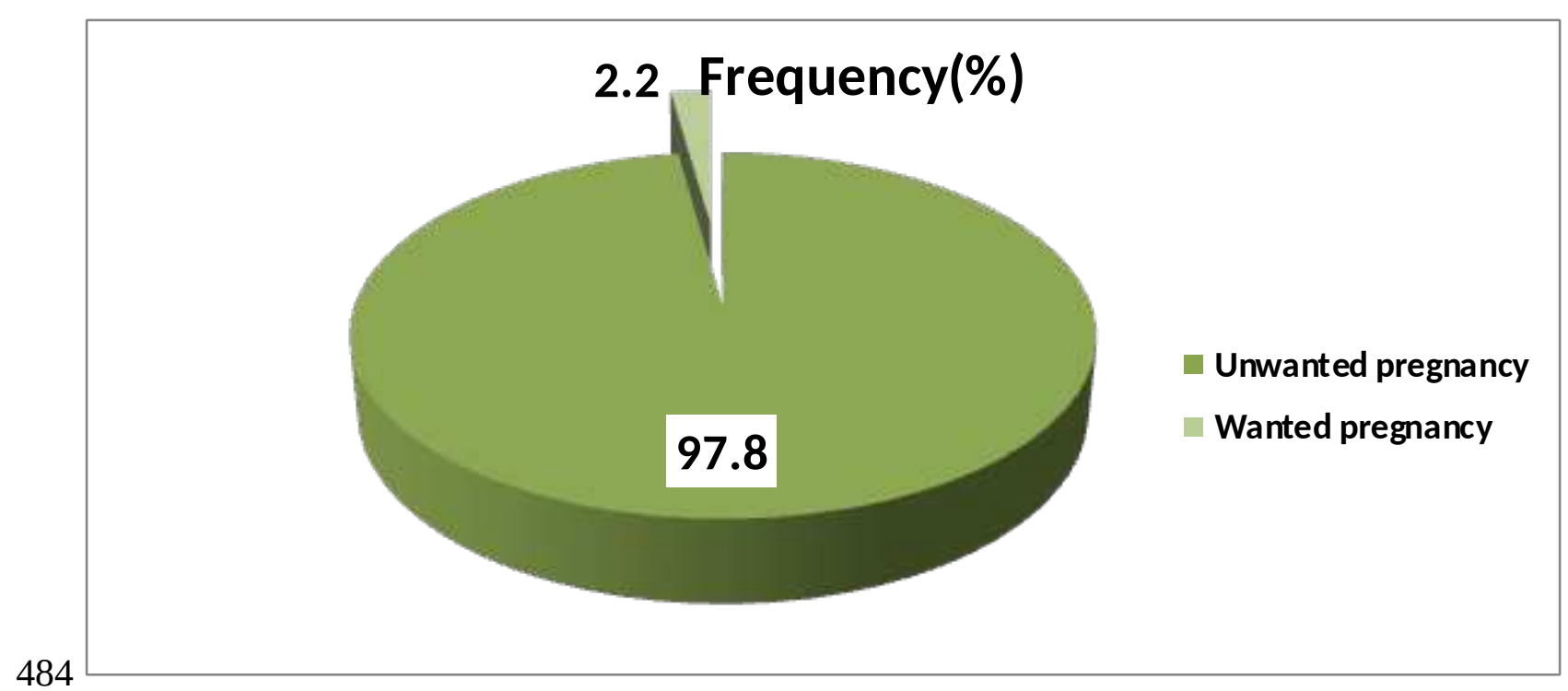

485Figure-1: Prevalence of Unwanted pregnancy among high school students

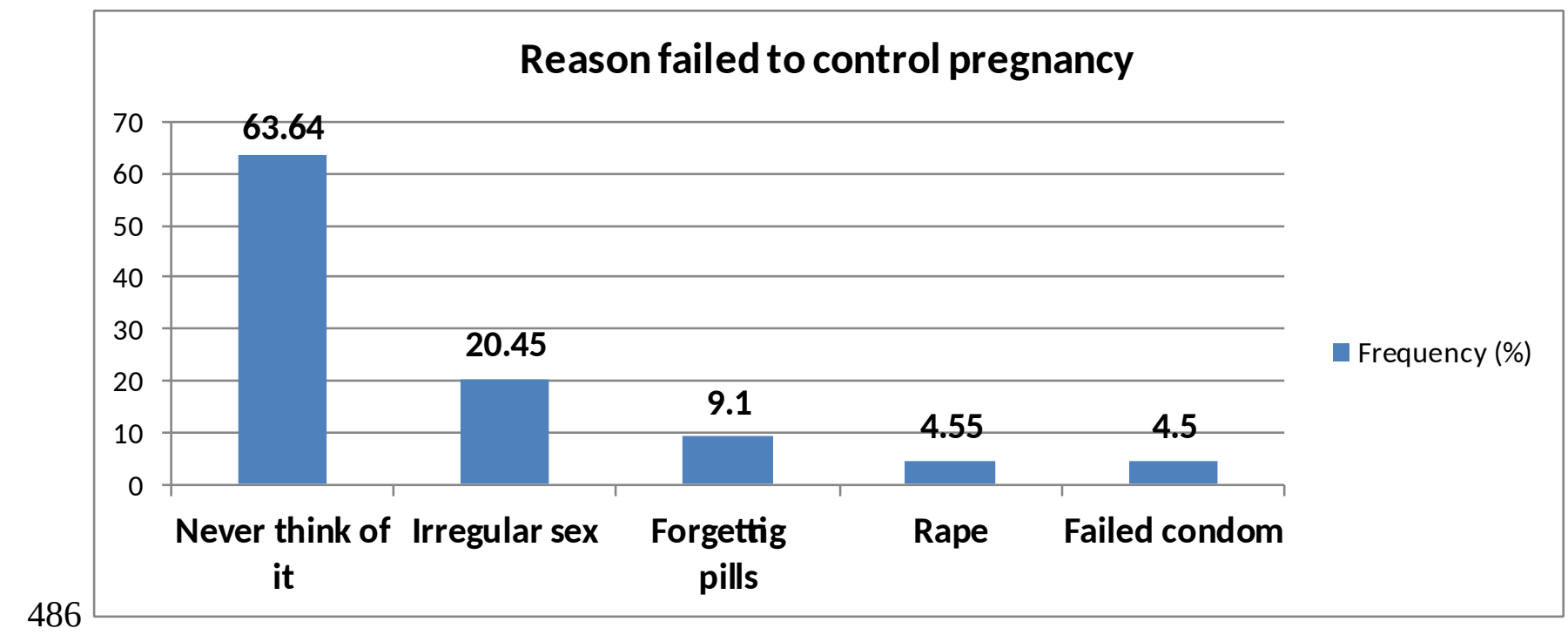

487Figure-2: Reason for unwanted pregnancies among high school students 
Figures

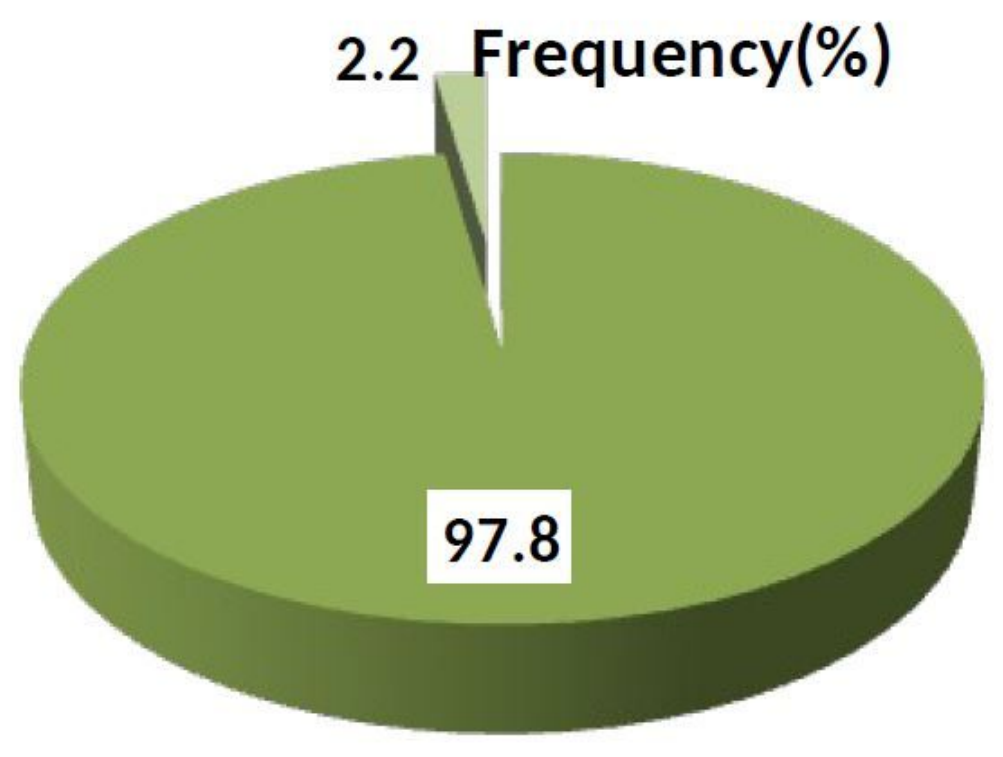

Unwanted pregnancy

Wanted pregnancy

\section{Figure 1}

Prevalence of Unwanted pregnancy among high school students

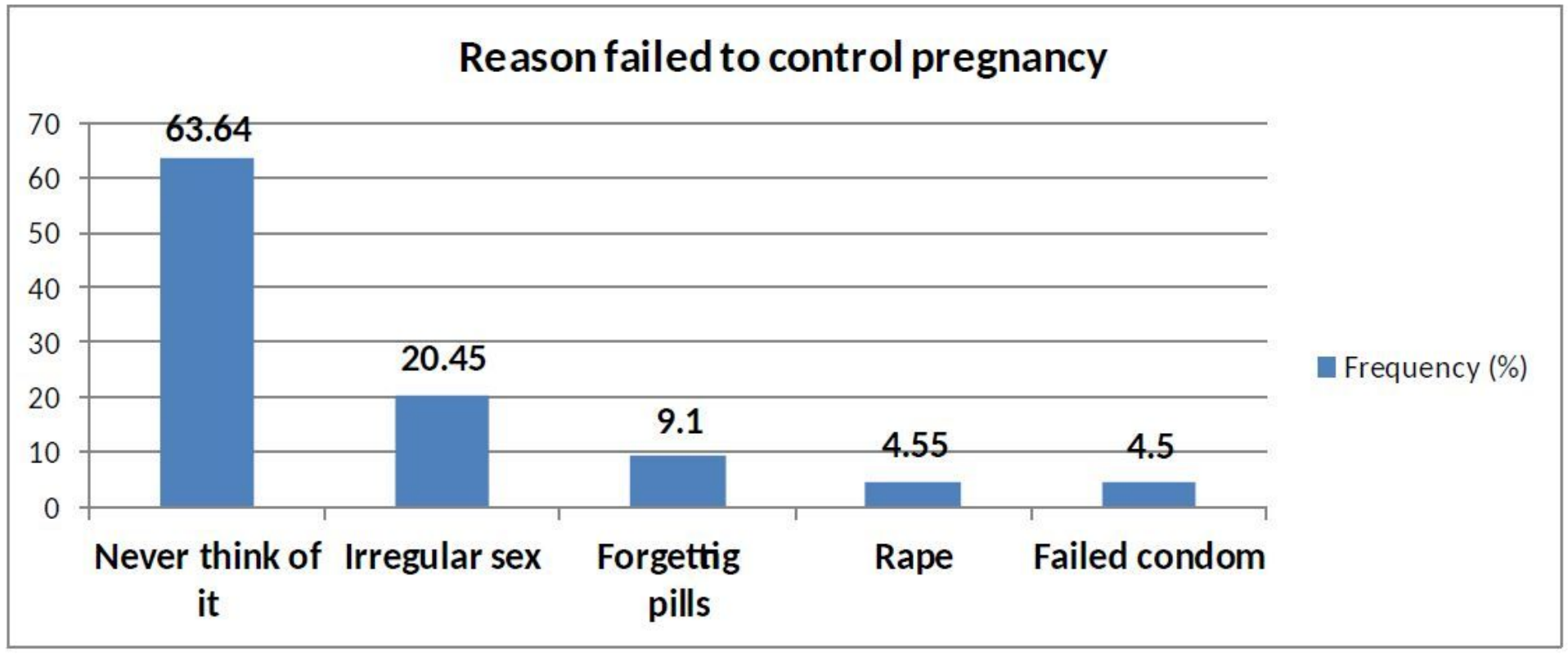

Figure 2

Reason for unwanted pregnancies among high school students

\section{Supplementary Files}


This is a list of supplementary files associated with this preprint. Click to download.

- Englishversionquestionnaire.docx 